\title{
Hemoglobin concentration; a pathway to frailty
}

\author{
Zara Steinmeyer ${ }^{1 *}$, Cyrille Delpierre ${ }^{2}$, Gaelle Soriano ${ }^{1}$, Armand Steinmeyer ${ }^{1}$, Loic Ysebaert $^{3}$, Laurent Balardy ${ }^{1}$ and \\ Sandrine Sourdet
}

\begin{abstract}
Background: Frailty and hemoglobin concentration, above what would be considered clinical anemia, are two common findings in older patients that lead to an increased risk of negative health outcomes. The objective of this study is to evaluate whether hemoglobin concentration is an independent predictor of frailty and investigate possible causal pathways with a focus on the relationship between inflammation or nutrition and hemoglobin concentration.

Methods: 1829 community-dwelling participants aged 65 years or older who visited the Toulouse frailty day hospital during 2011 and 2016 were included in this analysis. Patients underwent a comprehensive geriatric assessment and had a blood sample taken.

A series of multivariate logistic regression models were performed after minimizing potential influence from age, gender, kidney function, inflammation, cognition, nutritional status and certain socio-economic factors.

Results: Hemoglobin concentration and frailty are significantly associated after minimizing potential influence from other covariates $(p<0.005)$. An increase in one point of hemoglobin concentration is associated with a $14 \%$ risk reduction of being frail $(\mathrm{OR}=0.86,95 \% \mathrm{IC}=0.79-0.94)$. There was no evidence of a significant causal relationship between inflammation and nutritional status in the relationship between hemoglobin concentration and frailty status $(p>0.005)$.

Conclusions: Hemoglobin concentration is strongly associated with frailty in older adults. These results can have potentially important implications for prevention policies targeting frailty by identifying potential patients with high risk of adverse outcomes and functional outcomes.
\end{abstract}

Keywords: Frailty-hemoglobin-Anemia

\section{Background}

Frailty is a geriatric syndrome, prevalent in old age leading to an increased risk of negative health outcomes such as morbidity, mortality [1] and appears to be a transitional state in a dynamic process from robustness to disability [2]. It is defined as a state of increased vulnerability to stressors resulting from age-related decline in physiological reserve [3].

\footnotetext{
* Correspondence: steinmeyerzara@hotmail.fr

${ }^{1}$ Centre Hospitalier Universitaire de Toulouse, Geriatrics, Toulouse, France Full list of author information is available at the end of the article
}

As a clinical condition, it is characterized by the presence of more than three of the five Fried criteria (intentional weight loss, self-reported exhaustion, weakness, slow walking speed and low physical activity [4]) and is based on the relationship between biological and age associated markers linked in a cycle of frailty.

With demographic changes in society such as population aging, prevention of disability has risen to the fore of medical and economic concerns. Despite research and publications, mechanisms of frailty development remain poorly understood [5]

(c) The Author(s). 2020 Open Access This article is licensed under a Creative Commons Attribution 4.0 International License, which permits use, sharing, adaptation, distribution and reproduction in any medium or format, as long as you give appropriate credit to the original author(s) and the source, provide a link to the Creative Commons licence, and indicate if changes were made. The images or other third party material in this article are included in the article's Creative Commons licence, unless indicated otherwise in a credit line to the material. If material is not included in the article's Creative Commons licence and your intended use is not permitted by statutory regulation or exceeds the permitted use, you will need to obtain permission directly from the copyright holder. To view a copy of this licence, visit http://creativecommons.org/licenses/by/4.0/ The Creative Commons Public Domain Dedication waiver (http://creativecommons.org/publicdomain/zero/1.0/) applies to the data made available in this article, unless otherwise stated in a credit line to the data. 
Anemia and frailty are two common findings in geriatric patients and have been shown to be associated with similar poor health outcomes [6]. Anemia leads to diminished tissue oxygenation which may provoke diverse symptoms such as fatigue, weakness, and increased physical impairment. The symptoms of anemia are highly correlated with the symptoms associated to frailty and therefore may highlight a relationship between hemoglobin count and frailty $[7,8]$.

While the criteria as set out by the World Health Organization (WHO) are universally accepted, further study of anemia and frailty are frustrated by the continued debate of the cut off values chosen to define anemia in older populations $[9,10]$. Certain studies have shown that lower hemoglobin count, above what would be considered clinical anemia predicts negative health outcomes such as mortality, morbidity and low physical performance [10-12]. As such there is growing evidence that lower hemoglobin concentration is associated to frailty given their high prevalence together in an older population and their common health outcomes [13]. Whether low hemoglobin results in a state of frailty or vice versa, or are the symptoms of a common physiological state is yet to be investigated.

The close relationship between lower hemoglobin concentration and the definition of frailty suggests that lower hemoglobin concentration could be a stepping stone in explaining the frailty syndrome. Cecchi et al. show in their study that lower hemoglobin concentration is associated with the decline of self reported physical activity and muscular strength which are potential correlates of frailty [11].

However, whether this association is independent from increased prevalence of comorbidity, causing both low hemoglobin and reduced physical function is under debate. There are a few studies to this day on physiological mechanisms between hemoglobin concentration and frailty $[6,13,14]$. Frailty may be caused by the influence of a range of variables: sociodemographic, physical, biological, lifestyle and psychological factors [15]. Certain of these variables share a common influence on hemoglobin concentration such as nutritional deficiency, chronic renal failure and chronic inflammation [16].

Identifying the respective role of these potential confounders is necessary to study the linkages that exist in the relationship between frailty and hemoglobin concentration.

An important remaining issue is to disentangle common and separate pathways by which both nutritional and inflammation mechanisms can influence this relationship [16, 17].

This study aims to examine the pathways linking hemoglobin concentration to the presence of a frailty syndrome. Our objective was to evaluate whether hemoglobin concentration was an independent predictor of frailty and investigate possibe causal pathways, in particuliar the relationship between inflammation and nutrition with hemoglobin concentration.

\section{Methods \\ Participants}

A cross-sectional study was conducted on communitydwelling participants aged 65 years or older who visited the Toulouse frailty clinic during 2011 and 2016. Each patient was referred by a physician (general practitioner, geriatrician or specialist) who had reported signs or symptoms of frailty using the Gérontopôle Frailty Screeening tool [18].

Patients who were referred by a physician came to the Toulouse frailty day hospital for a multidisciplinary evaluation. Socio-demographic, anthropometric, detailed medical history, functional, frailty status and disability was recorded, as well as blood sample collection.

Patients who underwent a comprehensive geriatric assessment and had a blood draw were assessed for eligibility.

Patients referred for an onco-geriatric evaluation were excluded from the study because they have an on-going inflammatory state $(N=419)$, as well as patients treated with erythropoietin $(N=7)$.

\section{Outcome variable}

Frailty syndrome was evaluated according to the phenotype proposed by Fried et al. [4] based on the five criteria: unintentional weight loss, self-reported exhaustion, weakness, slow walking speed and low physical activity. Physical activity was the only adapted criterion as the Minnesota Leisure Time Questionnaire was not feasible in clinical practice. The questionnaire from the InChianti study on regular physical activity was used instead [19].

Weigth loss was defined as an unintentional loss of $>$ $5 \mathrm{~kg}$ in the past year [20].

Exhaustion was present, if the participant answered often or most of the time for the question « How often in the last week did you feel that everything that you did was an effort? " used in the Center for epidemiologic studies-Depression scale [21].

Low physical activity was described as an absent to minimal activity level in the past year.

Slow walking speed was defined by gender and height specific cut-off values proposed by Fried over a $4 \mathrm{~m}$ course at usual pace.

Weakness was evaluated by hand grip strength measured by a handheld dynamometer (Jamar, Inrvington, $\mathrm{NY}$ ) and based on gender, BMI specific cut-off values proposed by Fried [4]. Measures were done twice and on both hands, the average of the best results were used. 
Following this evaluation, participants were considered frail if they had more than 3 criteria, the others were considered non frail.

\section{Main exposure}

Blood tests were performed in the morning at enrollment in the frailty day clinic hospital. Samples were then sent and processed on automated instruments in the Toulouse University hospital laboratories. Hemoglobin concentration $\mathrm{g} / \mathrm{dl}$ was measured using the hematology analyzer Sysmex spectrophometry using cyanmethemoglobin method.

\section{Covariates}

Our study was designed to explore the relationship between frailty and hemoglobin count while controling for covariates that modify this relationship. This was done in order to see the pathways that exist in this relationship between frailty and hemoglobin concentration. Covariates likely to influence the main association tested between hemoglobin and frailty status were selected a pirori based on literature and added by order of influence. Covariates such as inherent demographics (age, sex) and health indicators were included. The other covariates were chosen based on their common association in the literature with frailty and hemoglobin concentration: kidney function, inflammation, cognition and nutritional status and socioeconomic positions [16, 22].

Two main types of covariates were distinguished:

\section{Clinical variables}

- Inflammation defined by a C-reactive protein level above $10 \mathrm{mg} / \mathrm{dl}$ [23]. Serum levels of high-sensitivity C-reactive protein (hs-CRP) is measured by immunoturbidimetry (Roche Cobas analyzer) [24].

- Renal function is estimated with glomerular filtration rate (GFR) calculated by using the chronic Kidney Disease Epidemiology Collaboration (CKDEPI) equation [25]. Serum creatinine level was assessed using a Diazyme's enzymatic method (Roche Cobas analyzer). The GFR categories were mapped to the categories retained by The Kidney Disease: Improving Global Outcomes (KDIGO) guidelines [26]. Normal kidney function was defined as a GFR $\geq 90 \mathrm{ml} / \mathrm{min}$ per $1.73 \mathrm{~m}^{2}$, mildly decrease GFR between 60 and $89 \mathrm{ml} / \mathrm{min}$ per $1.73 \mathrm{~m}^{2}$, moderate to severe decrease GFR $59-30 \mathrm{ml} / \mathrm{min}$ per $1.73 \mathrm{~m}^{2}$ and severe decrease GFR $>29 \mathrm{ml} / \mathrm{min}$ per $1.73 \mathrm{~m}^{2}$.

- The Mini nutritional assessment (MNA) was used to evaluate nutritionnal status [27]. A MNA score $\geq 24$ indicated an adequate nutritional status, a MNA score $<17$ a protein-calorie malnutrition and a
MNA score between 17and 23.5 a risk of malnutrition.

- The Mini Mental State Examination (MMSE) as developed by Folstein was used as a surrogate for cognitive function [28, 29]. A MMSE score above 26 was considered as absence or questionable dementia, between 21 to 25 for mild, 11 to 20 as moderate and under 10 as severe dementia [30]

\section{Social variables}

To assess the subjects's socio-economic position, we selected proxy variables such as the level of education. Education levels are categorized using the International Standard Classification of Education 2011 [31]. Education categories were defined as low (unschooled or primary education), medium (middle school to high school) or high (university level). We also collected living arrangements defined as either living alone or living with others (spouse, family,...).

\section{Statistical analysis}

Sample characteristics were first described. Data are reported as percentage or as mean \pm standard deviation.

We tested the normal distribution for the quantitative variables using the Shapiro wilk test.

Hemoglobin concentration was entered as a continuous measure as there was a linear relationship with frailty.

Bivariate analysis were used to assess the relationship between the covariates to hemoglobin and to frailty. Significance was tested using chi-square tests for categorical variables, Wilcoxon rank sum tests and Kruskall Wallis for continuous variables as appropriate.

Associations between age and hemoglobin were measured using the Pearson correlation coefficient.

To explore whether the increased risk of being frail was associated with hemoglobin concentration reflected the presence of comorbidity rather than constituing an additional risk factor of being frail, we further adjusted for kidney function, inflammation, cognition and nutritional status traditionnaly associated with frailty and hemoglobin concentration and we finally adjusted for socioeconomic position.

Multivariate logistic regression analysis with a forward selection was used to to examine the influence of these covariates further. Series of logistic regression models were performed.

Starting with the addition in the differents models of inherent individual covariates such as demographic data (Model 1), then biological parameters: renal function (Model 2), and inflammatory parameter (Model 3) and finally variables with environmental influence such as cognitive (Model 4), nutritional (Model 5) and socio economic variables (Model 6). 
In Model 7 we added in our regression model the interaction of inflammation and nutritional status with hemoglobin concentration corresponding to the full model.

We determined the respective statistical contributions of confounders in explaining the association between hemoglobin concentration and frailty by using a traditional approach to mediation.

This analysis was conducted to investigate the possible combined effects of inflammation and nutrition on hemoglobin concentration.

The analysis was performed using $\mathrm{STATA}^{\circ}$ version 11 (Stata Corp.,College Station, TX).

\section{Results}

Patients who underwent comprehensive geriatric assessment and had a blood draw were assessed for eligibility $(n=1905)$. The flow chart corresponding to the sample selection used for this study is presented in Fig. 1. A total of 76 patients were excluded: 70 patients due to lack of data on hemoglobine or frailty status and 6 because they had aberrant biological results.

At baseline, the mean age of the participants included in the study was 82.4 years $( \pm 6.5), 32.64 \%$ were male, and $38.87 \%$ completed at least high school (Table 1).

The most-common diseases was hypertension $52.05 \%$. Most of the patients did not have organ insufficiencies nor history of inflammatory diseases and $18.43 \%$ of the subjects had a history of cancer. Hemoglobin concentrations ranged from $7.8 \mathrm{~g} / \mathrm{dl}$ to $17.6 \mathrm{~g} / \mathrm{dl}$ with a mean $13.33 \mathrm{~g} / \mathrm{dl}( \pm 1.41)$.

Based on the WHO criteria for anemia, 20.83\% of participants were anemic at enrollement. $51.18 \%$ of the participants were non frail and were relatively autonomous with a mean score on the activities of daily living scale (ADL) of $5( \pm 1)$ and on the instrumental activities of daily living scale (IADL) of 5( \pm 2 ) [32].

Table 2 presents the results of multivariate logistic regression analysis conducted to study the relationship between hemoglobin and frailty.

The crude odds ratio (OR) between hemoglobin and frailty was $0.78(95 \% \mathrm{CI} 0.72-0.85)$ This OR of being frail decreased by $22 \%$ for an increase of hemoglobin of $1 \mathrm{~g} / \mathrm{dl}$ after adjustment for gender and age (model $1)$, as after inclusion of kidney function $(\mathrm{OR}=0.79$, 95\% CI $=0.73-0.86$ ) (model 2). This link persisted after the inclusion in the model of inflammation $(\mathrm{OR}=$ $0.81,95 \% \mathrm{CI}=0.75-0.89) \quad($ model 3$)$, cognition $(\mathrm{OR}=$ $0.82,95 \% \mathrm{CI}=0.75-0.89)$ (model 4 ), nutritional status $(\mathrm{OR}=0.86,95 \% \mathrm{CI}=0.79-0.94) \quad($ model 5$)$ and socio economoic variables $(\mathrm{OR}=0.86,95 \% \mathrm{CI}=0.79-0.94)$ (model 6).

Regarding the other determinants of frailty, the risk of being frail increased according to the stage of kidney disease, but this association was not statistically significative.

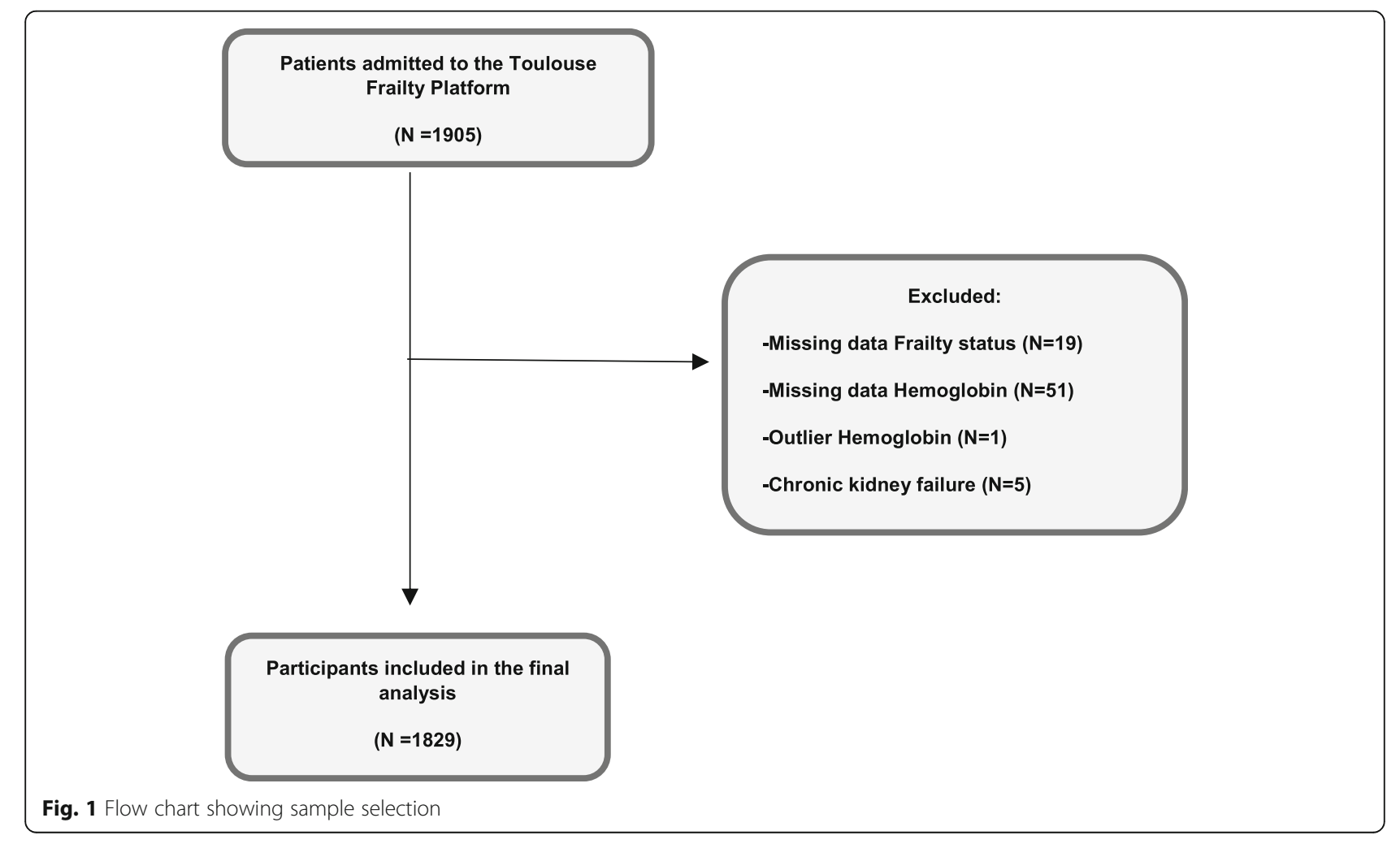


Table 1 Baseline characteristics of the study subjects

\begin{tabular}{|c|c|c|}
\hline \multicolumn{2}{|l|}{ Baseline Characteristic $(\boldsymbol{N}=1905)$} & \multirow[b]{2}{*}{ Included $(N=1829)$} \\
\hline & Available data & \\
\hline \multicolumn{3}{|l|}{ Socio-demographic } \\
\hline Age, mean (SD), years & 1905 & $82.44(6.50)$ \\
\hline Gender, Male, n(\%) & 1905 & $597(32.64)$ \\
\hline \multicolumn{3}{|l|}{ School education, n(\%) } \\
\hline Low level of education & 1811 & $677(37.01)$ \\
\hline Middle level of education & & $711(38.87)$ \\
\hline High level of education & & $357(19.52)$ \\
\hline \multicolumn{3}{|l|}{ Living arrangements $n(\%)$} \\
\hline Living alone & 1874 & $842(46.04)$ \\
\hline Living with others & & $959(52.43)$ \\
\hline \multicolumn{3}{|l|}{ Health conditions } \\
\hline Hypertension n(\%) & 1814 & $952(52.05)$ \\
\hline Diabetes mellitus n(\%) & 1814 & $261(14.27)$ \\
\hline Atrial arrhythmia n(\%) & 1811 & $278(15.20)$ \\
\hline Thrombo embolic disease $n(\%)$ & 1808 & $141(7.71)$ \\
\hline Cardiovascular disease $\mathrm{n}(\%)$ & 1810 & $269(14.71)$ \\
\hline Congestive heart failure n(\%) & 1813 & $103(5.63)$ \\
\hline Chronic respiratory disease $\mathrm{n}(\%)$ & 1269 & $17(0.93)$ \\
\hline Renal insufficiency n(\%) & 1269 & $57(3.12)$ \\
\hline Connectivitis n(\%) & 1814 & $62(3.39)$ \\
\hline Prebaseline cancer n(\%) & 1814 & $337(18.43)$ \\
\hline \multicolumn{3}{|l|}{ Examination findings } \\
\hline \multicolumn{3}{|l|}{ Frailty Fried's criteria } \\
\hline Non frail & 1886 & $936(51.18)$ \\
\hline Frail & & $893(48.82)$ \\
\hline \multicolumn{3}{|l|}{ Cognitive: MMSE score (\%) } \\
\hline No impairment $\geq 26$ & 1851 & $961(52.54)$ \\
\hline Mild impairment 21-25 & & $484(26.46)$ \\
\hline Moderate impairment 11-20 & & $310(16.95)$ \\
\hline Severe impairment 0-10 & & $27(1.48)$ \\
\hline \multicolumn{3}{|l|}{ Nutritional status } \\
\hline MNA score $\geq 24$ & 1847 & $1084(59.27)$ \\
\hline MNA score $17-23.5$ & & $610(33.35)$ \\
\hline MNA score $<17$ & & $81(4.43)$ \\
\hline ADL score(/6), median (IQR) & 1899 & $6(1)$ \\
\hline IADL score(/8), median (IQR) & 1884 & $6(4)$ \\
\hline \multicolumn{3}{|l|}{ Laboratory results } \\
\hline Hemoglobin, Mean \pm SD g/dl & 1854 & $13.33(1.41)$ \\
\hline Mean corpuscular volume, median (IQR), fl & 1854 & $91(6)$ \\
\hline White blood cell count, median (IQR), 10^3/cm & 1854 & $6.63(2.38)$ \\
\hline Platelets, median (IQR), 10^3/cm & 1832 & $231(80)$ \\
\hline Anemia $\mathrm{n}(\%)$ & 1832 & $381(20.83)$ \\
\hline C-reactive protein, median (IQR), mg/L & 1861 & $2.1(3.9)$ \\
\hline
\end{tabular}


Table 1 Baseline characteristics of the study subjects (Continued)

\begin{tabular}{|c|c|c|}
\hline \multicolumn{2}{|l|}{ Baseline Characteristic $(\boldsymbol{N}=1905)$} & \multirow[b]{2}{*}{ Included $(N=1829)$} \\
\hline & Available data & \\
\hline \multicolumn{3}{|l|}{ Renal function: CKD-EPI MD } \\
\hline Normal (eGFR $\left.\geq 90 \mathrm{ml} / \mathrm{min} / 1.73 \mathrm{~m}^{2}\right), \mathrm{n}(\%)$ & 1875 & $162(8.86)$ \\
\hline Mild decrease (eGFR 60-89 ml/min/1.73m²), n(\%) & & $1120(61.24)$ \\
\hline Moderate to severe decrease (eGFR 30-59 ml/min/1.73m²), n(\%) & & $484(26.46)$ \\
\hline Severe decrease (eGFR $\left.\leq 29 \mathrm{ml} / \mathrm{min} / 1.73 \mathrm{~m}^{2}\right), \mathrm{n}(\%)$ & & $43(2.35)$ \\
\hline
\end{tabular}

Inflammation was associated with a $125 \%$ risk of being frail (model 3) and this link persisted after inclusion of cognition $(\mathrm{OR}=2.26,95 \% \mathrm{CI}=1.58-3.25)$ (model 4$)$ as with the addition of nutritional status $(\mathrm{OR}=2.11$, $95 \% \mathrm{CI}=1.45-3.07$ ) (model 5). The risk of being frail increased according to the degree of severity of the cognitive state (model 4). For example the risk of being frail was 4.29 times more higher in the severly impaired $(\mathrm{OR}=4.29,95 \% \mathrm{CI}=1.60-11.51)$. This risk was significantly attenuated once adding nutritional status $(\mathrm{OR}=$ $1.98,95 \% \mathrm{CI}=0.71-5.51)$ and socio economic variables $(\mathrm{OR}=1.72,95 \% \mathrm{CI}=0.62-4.81)$.

Nutritional status was independantly associated with being frail (model 5). The risk of being frail was multiplied by 8 if the patient was in a state of malnutrition.

Education level was independently associated with being frail, the higher the level of education was, decreased the risk of being frail (model 6).

We found neither interaction between hemoglobin and nutrition to frailty, nor between hemoglobin and inflammation $(p>0.05)$.

\section{Discussion}

This study examines the influence of hemoglobin concentration on the subsequent risk of being frail after adjustment for a large range of confounders.

By this approach, many confounding factors that may explain pathways between hemoglobin and frailty were examined. The main finding of our study is that we have identified a significant association between hemoglobin count and frailty in this community dwelling population $(p<0.005)$. An increase in one point of hemoglobin concentration is associated with a $14 \%$ risk decrease of being frail $(\mathrm{OR}=0.86$ IC95\% 0.79-0.94).

This association remained significant after adjusting for age, gender, kidney function, inflammation, cognition, nutritional status and socio-economic position. The results of this study confirm results found in Corona et al. and Juarez-Cedillo et al.'s study but with a wider and older population sample $[6,13]$. Moreover, the decision to expand the number of variables under consideration in this study to include kidney function, inflammation, cognition, nutritional status and socio economic variables as they have been identified as potential confounders to frailty and hemoglobin concentration allows a more thorough understanding of this relationship. Thus, they should be adapted in future studies to further assess the causal relationship between these factors.

Looking at the relationship between hemoglobin concentration and disability, Chaves and al. have questionned the clinical appropriateness of the definition of anemia set by the WHO hemoglobin level < $12 \mathrm{~g} / \mathrm{l}$ for women and $<13 \mathrm{~g} / \mathrm{l}$ for men [33] given the independent adverse effects of low hemoglobin on mobility function [34]

This seems to be confirmed by the independent association between hemoglobin concentration and frailty status found in our study. Indeed low hemoglobin puts older adults at risk of poor oxygen delivery with exhaustion, fatigue and failing muscle strength [33, 35] Symptoms which are each individual criteria in the definition of frailty by Fried [4].

This hypothesis highlights another issue, which are the mechanisms at stake in lowering hemoglobin concentration.

This was our second objective, studying potential confounders between hemoglobin and frailty. Among all these factors identified: kidney function, inflammation, cognition, nutritional status and socio-economic factors there was no impact on the effect of hemoglobin on frailty after adjustment. This suggests that the relationship between hemoglobin concentration and frailty is independent of these variables and that further studies are required to identify the potential links between them.

Our hypothesis was that lower hemoglobin concentration and frailty are associated to a state of chronic inflammation. Indeed, frail older adults have often a poorer health status, chronic conditions and comorbidites leading to an active low grade of inflammation lowering hemoglobin concentration [36, 37]. However, 
$\begin{array}{ll}\text { Steinmeyer et al. BMC Geriatrics } & \text { (2020) 20:202 }\end{array}$

Page 7 of 10

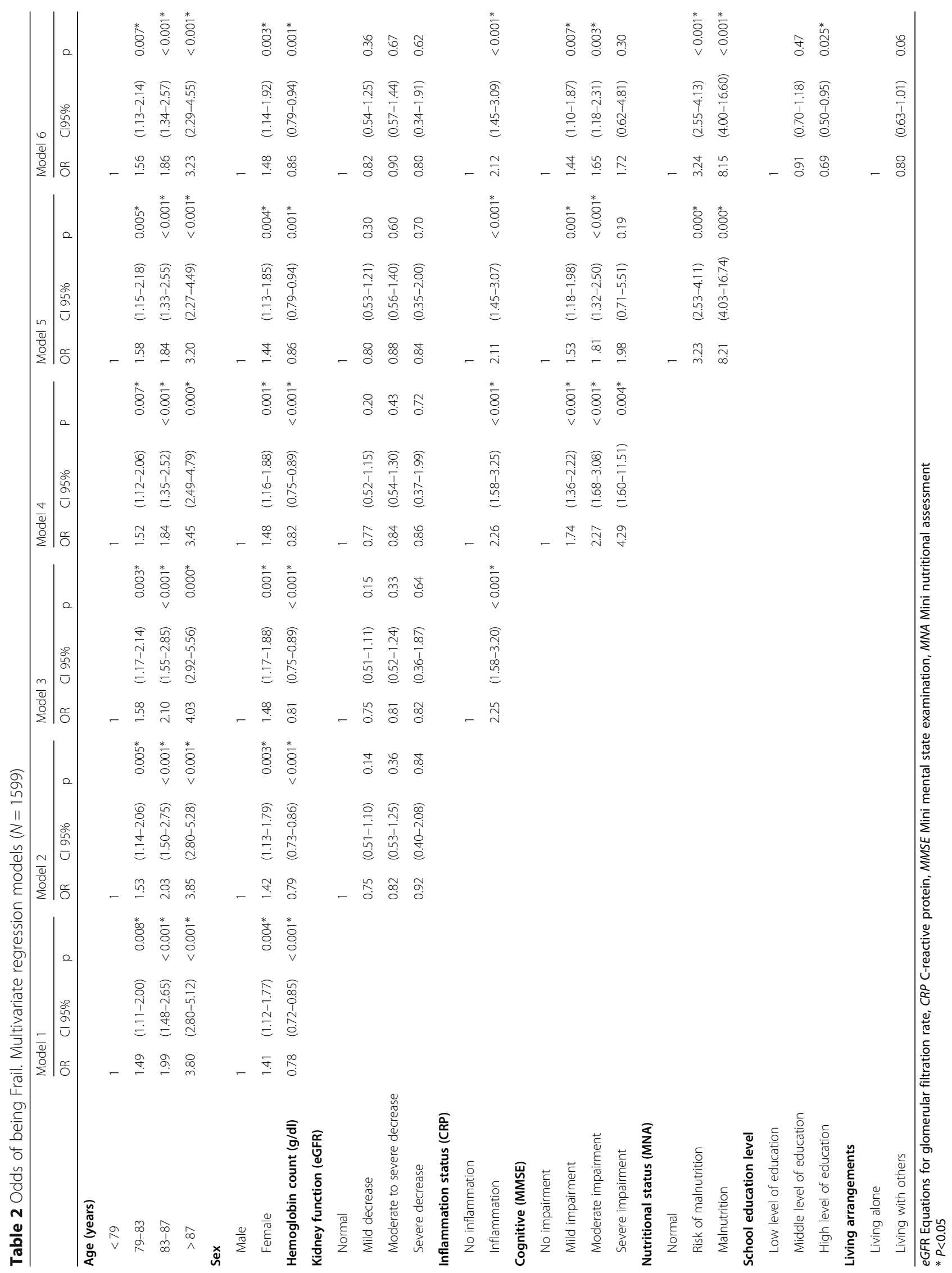


Walston et al. have provided evidence supporting an activation of inflammation with and without clinical comorbidities, suggesting that there is a direct relationship between frailty and inflammation [36]. Many studies have explored multiple inflammatory biomediators as potential mechanisms by which inflammation might promote lower hemoglobin [17, 38].

We chose in our study CRP as an inflammatory biomediator, after adding CRP in model 3 there was no impact on hemoglobin's odds ratio $(\mathrm{OR}=0.81$, IC95\%0.75-0.89 $p<0.005)$ and after studying the interaction between those two parameters the association was not significative $(p=0.14)$. The lack of relationship might be due to the cut off values used to define inflammation, or the inflammatory biomediator chosen [37, 39]. The pathogenesis of frailty and the role of inflammation remains incompletely understood. Leng et al.'s studied the potential role of neutrophils and monocytes in the pathogenesis of frailty as well as the role of interleukin-6 [14, 39]. There is a probable link between inflammation and frailty, our hypothesis was that maybe lower hemoglobin reflected this effect and could be a mediating factor we could follow to study this relationship. The question is if hemoglobin is a stigma of this relationship between inflammation and frailty or is it an independent actor in the frailty process.

We also studied the relationship between hemoglobin and nutritional status. Low hemoglobin count could be attributed to nutrient deficiencies (Iron, B12 and folate) [16], we kept in light this information and used the MNA [27] score as a proxy of the patient's nutritional state. Indeed, a patient with malnutrition is more likely to have nutrient deficiencies.

In our study, the risk of being frail increases according to their nutritional status in a bivariate analysis. However, the interaction between frailty, hemoglobine and nutritional status was not significative in this study.

The absence of link between nutritional status and hemoglobine is possibly explained by two hypotheses.

One hypothesis is that nutritional status as determined by the MNA score does not define vitamin deficiency, as patients with vitamin deficiencies are not necessarily malnourished and vice versa [40]. Another hypothesis is that the MNA is a certain type of nutrition screening tool and thus might not identify all situations of malnutrition in the elderly [41].

The main strength of this study is that data was prospectively measured with a large number of participants who underwent a comprehensive frailty assessment and that we used an explanatory model with series of logistic regression taking into account numerous potential confounders.
There are also a number of limitations that need to be considered.

Firstly, we took in account the major confounding factors of hemoglobin concentration, we did not investigate thouroughly all the causes of low hemoglobin concentration as this would have exceeded the purpose of our study.

Secondly, this is a monocentric study, all the study participants have been recruited through the Toulouse frailty day hospital. This may induce a selection and a representativeness bias.

Moreover, participants were referred by a physician (general practitioner, geriatrician or specialist) who had reported signs or symptoms of using the gerontopôle frailty screening tool (GFST) [18], so our findings might be difficultly extended to a general community-dwelling elderly population.

Finally, the cross-sectional nature of our study is the main limitation, a longitudinal analysis may shed light on the chronological and possible etiological relationship between hemoglobin and frailty.

\section{Conclusions}

Hemoglobin concentration is strongly associated with frailty in older adults. Addition of different covariates did not influence this relationship and the mechanisms involved in this relationship remain unclear. If hemoglobin concentration is an independent and a causal factor of frailty, improving concentrations of hemoglobin could potentially diminish the risk of frailty and thus detecting low hemoglobin above the score of anemia would be relevant.

Potential pathways linking hemoglobin to frailty deserve further investigations. These results can have potentially important implications for prevention policies targeting frailty, by identifying potential patients with high risk of adverse outcomes and functional outcomes.

\section{Abbreviations}

ADL: Activities of Daily Living; BMI: Body Mass Index; Cl: Confidence Interval; CKD-EPI: Chronic Kidney Disease Epidemiology Collaboration; CRP: C-Reactive Protein; GFR: Glomerular Filtration Rate; GFST: Gerontopôle Frailty Screening Tool; IADL: Instrumental Activities of Daily Living; KDIGO: The Kidney Disease Improving Global Outcomes guidelines; MMSE: Mini Mental State

Examination; MNA: Mini nutritional assessment; OR: Odds Ratio; WHO: World Health Organization

\section{Acknowledgements}

Not applicable.

\section{Authors' contributions}

"All authors have read and approved the manuscript". Specific areas of contributions are listed, using categories below: Study concept and design: ZS; CD; SS. Acquisition of data: ZS; SS. Analysis and interpretation of data: ZS: CD; SS; GS. Drafting of the manuscript: ZS; CD; SS. Critical revision of the manuscript for important intellectual content: ZS; CD; SS; AS; GS; LB; LY.

\section{Funding}

There are no sources of funding to declare for this study. 


\section{Availability of data and materials}

The datasets used and/or analysed during the current study are available from the corresponding author on reasonable request.

\section{Ethics approval and consent to participate}

The study protocol was approved by the ethic committee of the Toulouse University Hospital (CHU Toulouse). Consent of study participants was not obtained because data was collected on a routine basis, this was approved by the ethics committee.

\section{Consent for publication}

Not applicable.

\section{Competing interests}

The authors declare that they have no competing interests.

\section{Author details}

${ }^{1}$ Centre Hospitalier Universitaire de Toulouse, Geriatrics, Toulouse, France. ${ }^{2}$ Institut National de la Santé et de la Recherche Médicale UMR 1027, Toulouse, France. ${ }^{3}$ Institut Universitaire de Cancer de Toulouse, Toulouse, France.

\section{Received: 11 November 2019 Accepted: 28 May 2020}

Published online: 11 June 2020

\section{References}

1. Rockwood K, Howlett SE, Macknight C, Beattie BL, Bergman H, Hébert R, et al. Prevalence, attributes, and outcomes of fitness and frailty in community-dwelling older adults: report from the Canadian study of health and aging. J Gerontol A Biol Sci Med Sci. 2004;59(12):1310-7.

2. Lang P-O, Michel J-P, Zekry D. Frailty syndrome: a transitional state in a dynamic process. Gerontology. 2009;55(5):539-49.

3. Fried LP, Ferrucci L, Darer J, Williamson JD, Anderson G. Untangling the concepts of disability, frailty, and comorbidity: implications for improved targeting and care. J Gerontol Ser A. 2004:59(3):M255-63.

4. Fried LP, Tangen CM, Walston J, Newman AB, Hirsch C, Gottdiener J, et al. Frailty in older adults: evidence for a phenotype. J Gerontol A Biol Sci Med Sci. 2001;56(3):M146-56.

5. Fielding RA. A summary of the biological basis of frailty. Nestle Nutr Inst Workshop Ser. 2015:83:41-4.

6. Juárez-Cedillo T, Basurto-Acevedo L, Vega-García S, Manuel-Apolinar L, CruzTesoro E, Rodríguez-Pérez JM, et al. Prevalence of anemia and its impact on the state of frailty in elderly people living in the community: SADEM study. Ann Hematol. 2014;93(12):2057-62.

7. Chaves PHM, Semba RD, Leng SX, Woodman RC, Ferrucci L, Guralnik JM, et al. Impact of anemia and cardiovascular disease on frailty status of community-dwelling older women: the Women's health and aging studies I and II. J Gerontol A Biol Sci Med Sci. 2005:60(6):729-35.

8. Palmer K, Vetrano DL, Marengoni A, Tummolo AM, Villani ER, Acampora N, et al. The relationship between Anaemia and frailty: a systematic review and meta-analysis of observational studies. J Nutr Health Aging. 2018;22(8):96574.

9. Mindell J, Moody A, Ali A, Hirani V. Using longitudinal data from the health survey for England to resolve discrepancies in thresholds for haemoglobin in older adults. Br J Haematol. 2013;160(3):368-76.

10. Zakai NA, Katz R, Hirsch C, Shlipak MG, Chaves PHM, Newman AB, et al. A prospective study of anemia status, hemoglobin concentration, and mortality in an elderly cohort: the cardiovascular health study. Arch Intern Med. 2005;165(19):2214-20.

11. Cecchi F, Pancani S, Vannetti F, Boni R, Castagnoli C, Paperini A, et al. Hemoglobin concentration is associated with self-reported disability and reduced physical performance in a community dwelling population of nonagenarians: the Mugello study. Intern Emerg Med. 2017;12(8):1167-73.

12. Landi F, Russo A, Danese P, Liperoti R, Barillaro C, Bernabei $R$, et al. Anemia status, hemoglobin concentration, and mortality in nursing home older residents. J Am Med Dir Assoc. 2007:8(5):322-7.

13. Pires Corona L, Drumond Andrade FC, de Oliveira Duarte YA, Lebrao ML. The relationship between Anemia, hemoglobin concentration and frailty in Brazilian older adults. J Nutr Health Aging. 2015;19(9):935-40.
14. Leng S, Chaves P, Koenig K, Walston J. Serum interleukin- 6 and hemoglobin as physiological correlates in the geriatric syndrome of frailty: a pilot study. $J$ Am Geriatr Soc. 2002;50(7):1268-71.

15. Feng $Z$, Lugtenberg $M$, Franse $C$, Fang $X$, Hu S, Jin C, et al. Risk factors and protective factors associated with incident or increase of frailty amongcommunity-dwelling older adults: A systematic review of longitudinal studies. PLoS ONE. 2017;12(6). Available from: https://www.ncbi. nlm.nih.gov/pmc/articles/PMC5472269/. Accessed 10 June 2020.

16. Guralnik JM, Eisenstaedt RS, Ferrucci L, Klein HG, Woodman RC. Prevalence of anemia in persons 65 years and older in the United States: evidence for a high rate of unexplained anemia. Blood. 2004;104(8):2263-8.

17. Macciò A, Madeddu C. Management of Anemia of Inflammation in the Elderly. Anemia. 2012. Available from: https://www.ncbi.nlm.nih.gov/pmc/ articles/PMC3471391/. Accessed 10 June 2020.

18. Vellas B, Balardy L, Gillette-Guyonnet S, Abellan Van Kan G, Ghisolfi-Marque A, Subra J, et al. Looking for frailty in community-dwelling older persons: the Gérontopôle frailty screening tool (GFST). J Nutr Health Aging. 2013; 17(7):629-31.

19. Patel KV, Coppin AK, Manini TM, Lauretani F, Bandinelli S, Ferrucci $L$, et al. Midlife physical activity and mobility in older age. Am J Prev Med. 2006; 31(3):217-24.

20. Morley JE, Cruz-Jentoft AJ. Definitions of Sarcopenia. Sarcopenia: Wiley. 2012. p. 8-19. https://doi.org/10.1002/9781118338032.ch2.

21. Radloff LS. The CES-D scale: a self-report depression scale for research in the general population. Appl Psychol Meas. 1977;1(3):385-401.

22. Ng TP, Feng L, Nyunt MSZ, Larbi A, Yap KB. Frailty in older persons: multisystem risk factors and the frailty risk index (FRI). J Am Med Dir Assoc. 2014;15(9):635-42.

23. Palosuo T, Husman T, Koistinen J, Aho K. C-reactive protein in population samples. Acta Med Scand. 1986;220(2):175-9.

24. Young B, Gleeson M, Cripps AW. C-reactive protein: a critical review. Pathology (Phila). 1991;23(2):118-24.

25. Levey AS, Stevens LA, Schmid CH, Zhang YL, Castro AF, Feldman HI, et al. A new equation to estimate glomerular filtration rate. Ann Intern Med. 2009; 150(9):604-12

26. Stevens PE, Levin A. Kidney disease: improving global outcomes chronic kidney disease guideline development work group members. Evaluation and management of chronic kidney disease: synopsis of the kidney disease: improving global outcomes 2012 clinical practice guideline. Ann Intern Med. 2013;158(11):825-30.

27. Vellas B, Guigoz Y, Garry PJ, Nourhashemi F, Bennahum D, Lauque S, et al. The mini nutritional assessment (MNA) and its use in grading the nutritional state of elderly patients. Nutr Burbank Los Angel Cty Calif. 1999;15(2):116-22.

28. Folstein MF, Folstein SE, McHugh PR. 'Mini-mental state'. A practical method for grading the cognitive state of patients for the clinician. J Psychiatr Res. 1975;12(3):189-98.

29. Tombaugh TN, Mclntyre NJ. The mini-mental state examination: a comprehensive review. J Am Geriatr Soc. 1992;40(9):922-35.

30. Perneczky R, Wagenpfeil S, Komossa K, Grimmer T, Diehl J, Kurz A. Mapping scores onto stages: mini-mental state examination and clinical dementia rating. Am J Geriatr Psychiatry Off J Am Assoc Geriatr Psychiatry. 2006;14(2): 139-44.

31. Unesco. International Standard Classification of Education (ISCED) 2011. 2012

32. Katz S. Assessing self-maintenance: activities of daily living, mobility, and instrumental activities of daily living. J Am Geriatr Soc. 1983;31(12):721-7.

33. Chaves PHM, Ashar B, Guralnik JM, Fried LP. Looking at the relationship between hemoglobin concentration and prevalent mobility difficulty in older women. Should the criteria currently used to define anemia in older people be reevaluated? J Am Geriatr Soc. 2002;50(7):1257-64.

34. Beghé C, Wilson A, Ershler WB. Prevalence and outcomes of anemia in geriatrics: a systematic review of the literature. Am J Med. 2004;116(Suppl 7A):3S-10S.

35. Penninx BWJH, Pahor M, Cesari M, Corsi AM, Woodman RC, Bandinelli S, et al. Anemia is associated with disability and decreased physical performance and muscle strength in the elderly. J Am Geriatr Soc. 2004 52(5):719-24.

36. Walston J, McBurnie MA, Newman A, Tracy RP, Kop WJ, Hirsch CH, et al. Frailty and activation of the inflammation and coagulation systems with and without clinical comorbidities: results from the cardiovascular health study. Arch Intern Med. 2002;162(20):2333-41. 
37. Soysal P, Stubbs B, Lucato P, Luchini C, Solmi M, Peluso R, et al. Inflammation and frailty in the elderly: a systematic review and metaanalysis. Ageing Res Rev. 2016;31:1-8.

38. Baylis D, Bartlett DB, Patel HP, Roberts HC. Understanding how we age: insights into inflammaging. Longev Heal. 2013;2:8.

39. Leng SX, Xue Q-L, Tian J, Huang Y, Yeh S-H, Fried LP. Associations of neutrophil and monocyte counts with frailty in community-dwelling disabled older women: results from the Women's health and aging studies I. Exp Gerontol. 2009;44(8):511-6.

40. Araújo DA, Noronha MB, Cunha NA, Abrunhosa SF, Rocha AN, Amaral TF. Low serum levels of vitamin $B 12$ in older adults with normal nutritional status by mini nutritional assessment. Eur J Clin Nutr. 2016;70(7):859-62.

41. Bharadwaj S, Ginoya S, Tandon P, Gohel TD, Guirguis J, Vallabh H, et al. Malnutrition: laboratory markers vs nutritional assessment. Gastroenterol Rep. 2016;4(4):272-80.

\section{Publisher's Note}

Springer Nature remains neutral with regard to jurisdictional claims in published maps and institutional affiliations.

Ready to submit your research? Choose BMC and benefit from:

- fast, convenient online submission

- thorough peer review by experienced researchers in your field

- rapid publication on acceptance

- support for research data, including large and complex data types

- gold Open Access which fosters wider collaboration and increased citations

- maximum visibility for your research: over $100 \mathrm{M}$ website views per year

At BMC, research is always in progress.

Learn more biomedcentral.com/submissions 